\title{
CUANDO LOS ESCOMBROS GENERAN VALOR Del control de las alteraciones a la valorización del legado minero
}

\section{WHEN DEBRIS GENERATES VALUE \\ From the control of alterations to the valorisation of mining heritage}

Tsiouti, Andri

Departamento de Urbanismo, Universidad Politécnica de Cataluña

\section{RESUMEN}

La crisis general de la minería en los años 60 y 70 deja una inmensa cantidad de vestigios dispersos por toda España. Las extracciones alteran gravemente el medio natural, lo que se intenta paliar con disposiciones legales que se van actualizando desde los 80 . Se realizan proyectos de restauración en varias explotaciones, que al principio se limitan a intervenciones sencillas de corrección paisajística. Al crecer la sensibilidad ambiental, aparecen proyectos más ambiciosos. Al mismo tiempo, las minas se empiezan a apreciar como lugares de memoria e identidad local. Sin embargo, la preocupación por eliminar la contaminación da lugar, a menudo, a la destrucción de este patrimonio. Este artículo examina primero la evolución de la legislación minera en relación con los proyectos de restauración. $Y$ a continuación plantea algunas reflexiones sobre el difícil equilibrio entre la remediación ambiental y la valorización patrimonial en la experiencia española.

Palabras Clave: patrimonio minero, restauración ambiental, legislación minera, Ríotinto

\begin{abstract}
The general crisis of mining sector in the 60 s and 70s leaves a huge amount of traces dispersed throughout Spain. Besides that, extractive operations provoke serious alterations on the natural environment that start to be controlled by legal regulations which are being renovated since the $80 \mathrm{~s}$. In this context, restoration works get place in various mining sites which in the beginning are limited to simple landscape interventions. Since environmental awareness increases, some more ambitious projects start to appear. At the same time, mines start to be valued as places of memory and local identity. However, the necessity to eliminate contamination results, in many cases, to the destruction of mining heritage. The article examines the evolution of mining legislation in relation to restoration projects. And secondly, some reflections are offered on the difficult balance between environmental remediation and heritage valorisation through examples from Spain.
\end{abstract}

Key words: mining heritage, environment restoration, mining legislation, Riotinto 


\section{Introducción}

El presente trabajo forma parte de una investigación más amplia que analiza la revalorización de los paisajes mineros frente al declive de la actividad extractiva. Tiene como punto de partida un trabajo previo (Tsiouti, 2018) ${ }^{1}$, donde el estudio de experiencias españolas heterogéneas permite identificar tres etapas claras en los procesos de recuperación: la primera, de mera restauración ambiental de los terrenos exigida por ley; la segunda, la puesta en valor del patrimonio minero; y una última más completa que, además de las intervenciones anteriores, procura poner el legado minero al servicio de la comunidad local, implicándola en el proceso. Sin embargo, la experiencia muestra que estas actuaciones son largas y complejas, condicionadas por las características particulares de cada lugar, y acaban generando paisajes muy diversos. Esta consideración nos invita a plantear algunas cuestiones relevantes: teniendo en cuenta la inmensa cantidad de minas abandonadas que existen en España y en el mundo, ¿cuáles son los factores que facilitan su reaprovechamiento? Frente al rechazo y la degradación, ¿qué factores inciden para que ciertos paisajes se pongan en valor? ¿Cómo se hace partícipe a la comunidad local de la recuperación?

El objetivo final es descubrir las claves que garantizan revalorización de los lugares de la minería y su puesta al servicio del bien común. Para ello se examinan proyectos realizados en España y algunas referencias internacionales.

España tiene una larga trayectoria en la actividad minera desde la antigüedad. Con el aumento de la demanda internacional y el paulatino auge del sector en el primer tercio del siglo XX llega a ser un gran exportador de minerales. Sin embargo, con la transformación tecnológica, la relocalización de las industrias y el agotamiento de los recursos, la minería entra en una crisis sin precedentes, tanto en Europa como en España, que culmina en los 60 y 70 . El cierre definitivo de la mayoría de las explotaciones deja extensos paisajes e instalaciones en desuso, generando, a menudo, impactos ambientales y sobre la salud.

En ese mismo período, a inicios de los 70 , crece la conciencia medioambiental. La preocupación por el impacto de la minería motiva la integración de la variante medioambiental en la actividad extractiva, a través de un marco normativo europeo, con medidas dirigidas a la eliminación de la contaminación. Varios países lo adoptan y empiezan a redactar disposiciones que procuran controlar los efectos durante la explotación, por un lado, y por otro, a garantizar la corrección de los terrenos afectados. España incorpora dicha preocupación a inicios de los años 80 , obligando, a partir de entonces, a prácticas restauradoras. Al principio se limitan a intervenciones mínimas de eliminación de riesgos y corrección de las alteraciones pero, con la incorporación paulatina de regulaciones más exigentes, aparecen proyectos relevantes que, además de devolver los terrenos a un estado lo más parecido posible al original, les aportan calidades ambientales y posibilidad de aprovechamiento.

La crisis del sector minero coincide en el tiempo con la creciente tendencia hacia el turismo cultural y la idea de conservar los testimonios del pasado. El concepto de patrimonio, que hasta finales del siglo XIX se limita a monumentos aislados y desvinculados de su contexto, va ensanchando sus límites hasta incorporar todo aquello que refleja los diversos procedimientos que transforman el territorio. Nace pues una consciencia más amplia de los valores del patrimonio que, al recordar el esfuerzo comunitario de épocas pasadas por poner la naturaleza al servicio del hombre, se percibe como el legado de una comunidad, del trabajo y del estilo de vida que conforman su propia cultura. Los ámbitos cotidianos donde se produce esta herencia se aprecian como lugares de memoria e identidad, y el reconocimiento de la estrecha relación entre cultura y paisaje abre el camino hacia la definición del concepto del paisaje cultural (Sabaté, 2005). En este contexto, los paisajes de la minería adquieren cierto protagonismo. Los problemas socioeconómicos que sufren las zonas exmineras y la consciencia del potencial que brindan para estimular un nuevo desarrollo despiertan un creciente interés para la reactivación de estos lugares que hasta entonces se rechazan como espacios saturados y contaminantes. En busca de un nuevo impulso frente al declive del sector productivo, empiezan a aparecer las primeras prácticas de puesta en valor a nivel internacional, y pocos años después, en España, a finales

\footnotetext{
${ }^{1}$ Más información en TSIOUTI, A y SABATÉ B., J. (2018)
} 
de los 70. Desde entonces, conjuntos mineros son objeto de actuaciones en todo el país, y varían desde la redacción de inventarios, planes de restauración e intervenciones mínimas de corrección de los terrenos, hasta iniciativas más complejas de reactivación y valorización del patrimonio.

Este artículo aspira a descubrir el papel que desempeña la legislación minera en la recuperación de las minas, examinando las disposiciones legales que se van incorporando desde los 80 y su correlación con los proyectos realizados. Las experiencias muestran que la obligación de controlar las alteraciones y paliar los efectos contaminantes introduce ciertas condiciones y limitaciones en los procesos, pero a su vez abre el camino hacia un nuevo futuro para estos lugares que, a pesar de su potencial, en su mayoría se encuentran abandonados y degradados. Para vincular la evolución de las intervenciones con la renovación de la normativa, se exponen ejemplos en orden cronológico, que parten por actuaciones más sencillas y prosiguen con otras más complejas. Al mismo tiempo, se examina el difícil equilibrio que supone la restauración ambiental y la preservación de los vestigios. Intuimos que la alta preocupación por paliar la contaminación de los terrenos y devolverlos al estado natural previo hace que las actuaciones ambientales predominen en la puesta en valor, y que el legado minero a menudo se pierda. No obstante, parece que a pesar de las intervenciones radicales que exige la paliación de la contaminación, la existencia de valores patrimoniales en los paisajes mineros hace posible la compatibilización de las actuaciones ambientales con su puesta en valor. Se pretende comprobar esta última hipótesis a través del estudio del ejemplo pionero de las Minas de Riotinto. El objetivo final es demostrar cómo la recuperación ambiental se puede compaginar con la preservación del patrimonio minero, convirtiendo los conjuntos en lugares de memoria e identidad local que estimulan un nuevo desarrollo socioeconómico.

\section{Del apogeo al rechazo: la extracción como origen de contaminación}

La actividad minera, como toda actividad humana, en cualquier periodo que se considere, deja su huella en el paisaje y lo acaba alterando. Los avances en las técnicas y la intensificación de los procesos marcados por la Revolución Industrial producen impactos cada vez mayores y continuados, que repercuten en el entorno, no solo durante las operaciones extractivas, sino también después de su finalización. La falta de normativa hace que las labores se realicen sin ninguna precaución, ni tampoco obligación de restaurar los espacios. Las empresas explotadoras los abandonan en el estado en el que se encuentran, cargados de escombros e instalaciones que quedan obsoletas (Tandy, 1979).

La heterogeneidad de los paisajes mineros hace que la magnitud de los perjuicios dependa del tipo de mineral, el método de extracción, la topografía, la extensión y duración de las obras, entre otros factores. Existen pues minas que implican un nivel de contaminación muy elevado, como las de carbón, que por sus repercusiones tan graves sobre el medio ambiente se consideran entre las fuentes principales de contaminación en Europa. La polución de la atmósfera, la contaminación de las aguas, la afección de los terrenos por los esquistos carboníferos, el cambio irreversible de la topografía por las profundas cortas y la destrucción de los ecosistemas son muestra de la gravedad que pueden alcanzar las explotaciones de este tipo y otras parecidas, como las de hierro, oro, cobre, azufre, etcétera. La explotación salinera, por otro lado, debido al uso de energías limpias para la obtención de la sal, tiene efectos menores, y en cambio generan valores ecológicos y paisajísticos (Luengo y Marín, 1999). El grado de alteración de los terrenos y los impactos de las explotaciones mineras sobre el medio natural y social, influyen inevitablemente en el momento de implementar un plan de restauración, de modo que cuanto más contaminado acaba un conjunto minero, más se complica su recuperación.

Al estar mucho tiempo en desuso, los equipamientos mineros implican riesgos físicos, como colapsos o derribos de pozos y edificaciones degradadas, hundimientos, inundaciones y otros problemas de seguridad. A estos se suman los efectos visuales, especialmente los cráteres de extracción y las profundas cortas en las explotaciones a cielo abierto, además de los montones de escombros que acaban generando una topografía 
artificial. Las minas de mayor impacto suponen además riesgos químicos, provocados por el uso de productos tóxicos $u$ otros materiales nocivos durante la explotación o por componentes residuales que se depositan en las escombreras (Escribano, 2015). Aunque no se ven a primera vista, estos efectos tienen una trascendencia mucho más grande y repercuten considerablemente sobre el medio ambiente y la salud humana, mientras que su eliminación exige procesos muy laboriosos.

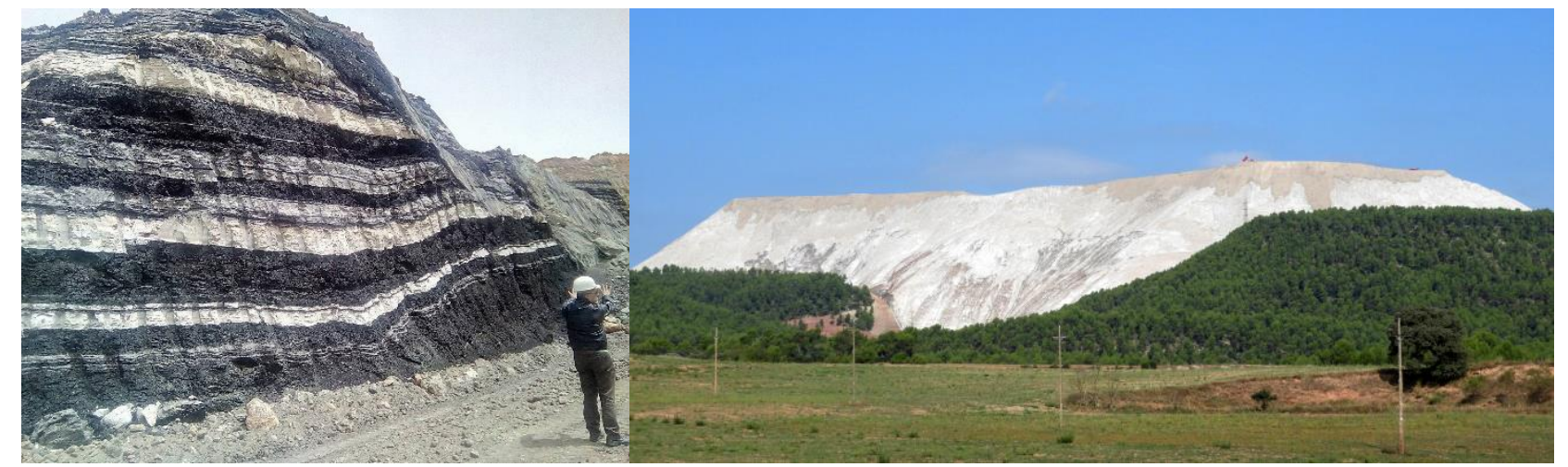

Fig. 01 Extracción de lignito en Ptolemaida, Grecia. Fuente: Archivo personal de Christos Christoforou.

Fig. 02 Escombrera en las explotaciones de potasa de Suria, Cataluña.

Fuente: https://diario16.com/la-explotacion-la-potasa-catalunya-una-fiebre-del-pasado-amenaza-territorio-presente/

\section{La normativa como estímulo para la recuperación}

Aunque a partir de los inicios del siglo XIX se empiezan a aprobar algunas medidas para regular la minería, son escasas e ineficientes para resolver los problemas provocados. No es hasta el 1973 que España establece la primera Ley de Minas (Ley 22/1973 de 21 de julio). Aunque todavía no hace mención a prácticas de recuperación, introduce órdenes que pretenden equilibrar la extracción con la protección medioambiental y se considera pionera en este aspecto. Con esta primera normativa las empresas se empiezan a ser más conscientes de las repercusiones de su actividad y adoptan prácticas más respetuosas con el medio ambiente, dado que los costes ambientales pueden suponer penalizaciones o convertirse en amenaza para su futuro, como en el caso de la Sierra Minera de Cartagena-La Unión donde las consideraciones ambientales significan el cierre definitivo de las explotaciones en 1991 (Saiz de Omeñaca, 1996).

Es a partir de la incorporación de España a la Unión Europea y la transposición de sus directivas, cuando se empiezan a efectuar restauraciones de las zonas explotadas. La preocupación por las alteraciones paisajísticas y geomorfológicas, especialmente en las explotaciones a cielo abierto, impulsa la promulgación del Real Decreto 2994/1982, de 15 de octubre, con el que se establece por vez primera la exigencia de restaurar los espacios afectados por la actividad minera. El Decreto obliga a la redacción de un plan de restauración, tanto para las nuevas explotaciones, como para las activas, con medidas de corrección de las alteraciones físicas y visuales: acondicionamiento de las superficies, minimización del riesgo de erosión, almacenamiento de los residuos mineros, estudio del impacto y medidas protectoras del medio ambiente. $Y$ además exige que la restauración cuando las minas todavía están activas, lo que facilita su ejecución y reduce los impactos (BOE, 1982). Esto se hace más común en España a partir de los 80-90. En las canteras de caliza de Cuchía, en Cantabria, se implementa un plan de restauración paisajística dedicado a reintegrar el espacio alterado en su entorno natural. Una vez presentado el estudio de Impacto Ambiental (1983) y luego el Plan de Restauración (1988) comienza en 1991 un trabajo progresivo en las zonas explotadas que se van agotando hasta su cierre definitivo en 2006. Primero se aporta tierra al suelo y a los acantilados desnudos y luego se realiza su revegetación con plantas autóctonas, recuperando así el hábitat natural. Además de la corrección del terreno como exige la ley, se forman lagunas y estanques, se introducen ecosistemas palustres y vida animal y se crean recorridos por el antiguo yacimiento calizo, generando un espacio de mayor calidad paisajística. 


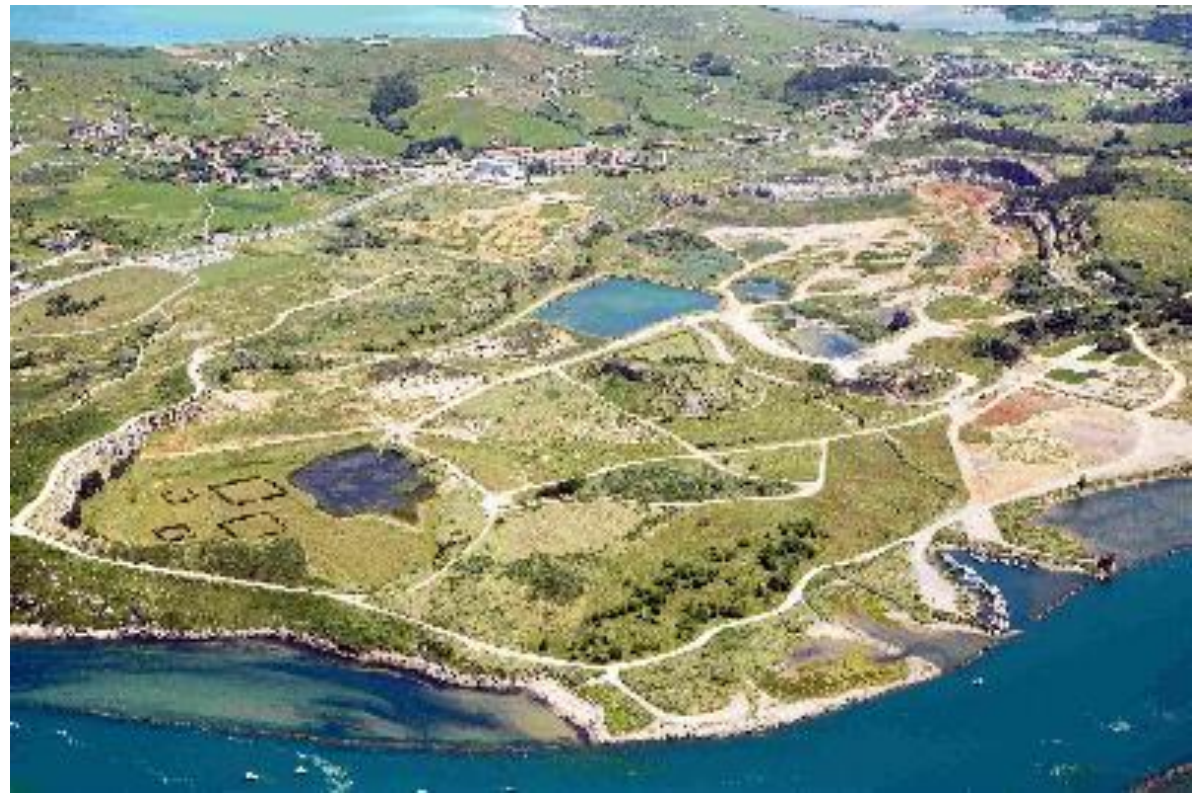

Fig. 03 Recuperación paisajística de las canteras de Cuchía. Fuente: (Solvay)

Al no tener carácter retroactivo, la Ley de Minas excluye las explotaciones que se cierran antes del 1973, con lo que una inmensa cantidad de minas quedan abandonadas y se degradan, constituyendo a menudo fuente de contaminación. Sin embargo, el contexto geográfico y las posibilidades de reutilización para fines diversos, entre otros factores, pueden favorecer su recuperación, independientemente de la normativa. Cabe citar como ejemplo la reconstrucción geomorfológica de la cantera de arenas La Revilla, en Segovia, premiada a nivel nacional. La finalización de la extracción deja un frente, una plataforma y escombreras sometidos a procesos de erosión, en medio de un paisaje rural de gran calidad ambiental. En 1995 la empresa explotadora pone en marcha la restauración de la cantera para su reintegración al entorno y su posterior utilización para fines similares a los que tenía antes. Una vez reconstruido el terreno, aprovechando los estériles mineros, se crea una nueva capa vegetal con siembra de semillas y fertilizantes que se seleccionan cuidadosamente, según los análisis que se realizan para garantizar la satisfactoria evolución del conjunto. Al pie del antiguo frente se construye un conducto de retención de sedimentos. Se genera así una ladera de perfil similar al de los relieves circundantes. La superficie revegetada permite la evolución de comunidades vegetales y en una parte se recupera la antigua actividad de cultivo vitivinícola.
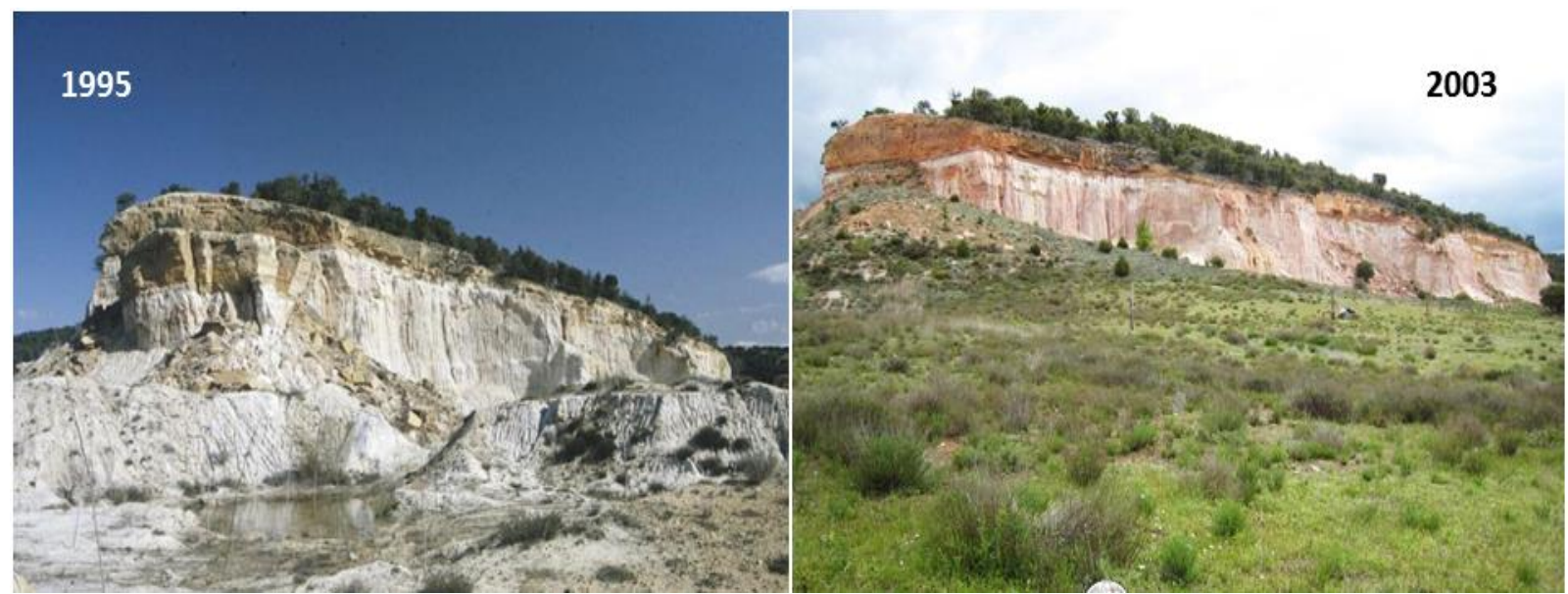

Fig. 04 Antes y después de la restauración de la cantera de La Revilla en Segovia. Fuente: Dpto. de Geodinámica, UCM. 
La concienciación de los graves impactos de la minería de carbón, que en aquel período está en auge, motiva el establecimiento de una normativa específica dos años después. Se trata del Real Decreto 1116/1984, de 9 de mayo, desarrollado mediante una Orden del mismo año, que regula el contenido de los planes de explotación y restauración de las explotaciones carboníferas a cielo abierto. Se introducen normas más rigurosas que, además de la corrección del aspecto visual y físico del paisaje, incorporan la protección de las aguas subterráneas y superficiales de sustancias contaminantes, el diseño de las escombreras y la disposición de estériles en vertederos interiores para facilitar su reintegración y futuro aprovechamiento y la protección de la población (BOE, 1984). La instauración de estas últimas regulaciones da pie a algunas actuaciones interesantes, entre las que destacan las restauraciones de ENDESA en sus centros mineros. Este es el caso de las minas de Andorra (Teruel), explotadas entre 1972 y 2012. Para reducir el tiempo entre la explotación y la restauración, se opta por el método de transferencia por paneles, donde los huecos ya explotados se rellenan con estériles mientras se van abriendo los siguientes, implementando lo que básicamente indica la Orden de 1984 sobre la disposición de los residuos mineros. A pesar de la falta de experiencia y metodologías al principio (cuando las escombreras restauradas muestran una estética artificial y menos integrada en el entorno), con la evolución de las obras se va adoptando un diseño más armonioso y naturalizado. Una vez estabilizadas y acondicionadas las superficies, se procede a la creación de un paisaje de alta calidad ambiental, yendo más allá de las exigencias legales. Después de instalar las infraestructuras necesarias para la protección de las aguas, se utilizan cultivos y especies forestales y se crean humedales. Tras un proceso largo y progresivo, concluido en 2016, las intervenciones dan lugar a un nuevo ecosistema compuesto por 865 hectáreas restauradas y adaptadas al uso tradicional agrícola de la zona (Hermosillo et al., 2017).

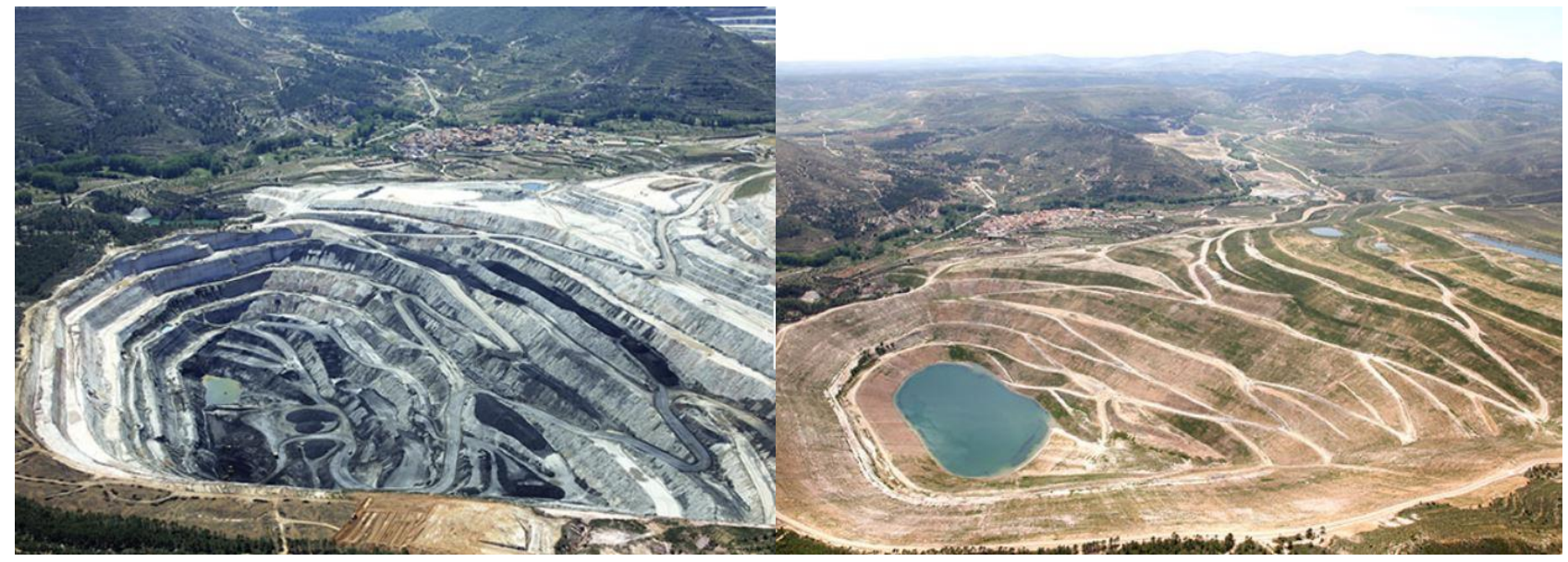

Fig. 05, 06 Restauración de las explotaciones de lignito en Andorra: antes y después Fuente: (Hermosillo et al, 2017)

Mientras las primeras prácticas se limitan a la corrección de las alteraciones visuales, las normativas posteriores se hacen más estrictas, con la intención de paliar los problemas en su totalidad. Con esto los explotadores empiezan a prestar más atención a los efectos químicos y contaminantes de su actividad y llevan a cabo, en ciertos casos, intervenciones más potentes, que acaban creando lugares con calidad ecológica y adaptados a nuevas funciones.

En 2009 se promulga el Real Decreto de 12 de junio sobre gestión de los residuos de las industrias extractivas, protección y rehabilitación del espacio afectado por actividades mineras, que aporta mayor claridad y regulación sistemática que las directivas del 1984. Incorpora la Directiva² de la Unión Europea del 2006 que se instaura en el contexto de la política comunitaria de medio ambiente. El objetivo general es el

${ }^{2}$ Directiva 2006/21/CE del Parlamento y del Consejo publicada en el "Diario Oficial de la Unión Europea" el 11 de abril de 2006 sobre gestión de los residuos de industrias extractivas y por la que se modifica la Directiva 2004/35/CE. 
establecimiento de medidas, procedimientos y orientaciones para prevenir o reducir los efectos al medio ambiente: las aguas, el aire, el suelo, la fauna, la flora y el paisaje. Pero sobre todo da enfoque a la gestión de los residuos, obligando a la rehabilitación de los emplazamientos donde se sitúan las instalaciones. E incluso, se presta atención a la seguridad de las personas, estableciendo una política de prevención de accidentes y redacción de planes de emergencia. Cabe señalar que en esta directiva se habla de rehabilitación en vez de restauración, como concepto más exacto y apropiado que se refiere a un tratamiento integral de los terrenos afectados y su adaptación a usos adecuados. Asimismo, incorpora medidas que garantizan la responsabilidad de las empresas posterior al cierre y exige la aplicación de las mejores técnicas disponibles de seguimiento y de control. Para mejorar la eficiencia de las operaciones, la Comisión Europea promueve un intercambio de información científica, técnicas y metodologías eficientes entre los miembros (BOE, 2009).

La sistematización y mejora de las técnicas consigue resultados muy positivos y se materializa en proyectos muy diversos en toda España, con un ritmo acelerado en los últimos años. Las minas más emblemáticas dan lugar a proyectos patrimoniales como museos, parques mineros, centros de interpretación, galerías acondicionadas para fines didácticos y recreativos, rehabilitación de instalaciones mineras y otras iniciativas, públicas o privadas. La preocupación por eliminar la contaminación hace olvidar, a menudo, el cuidado en mantener de las huellas de la minería. Las minas a cielo abierto, por ejemplo, por la incidencia de efectos erosivos y contaminantes, se someten a una remodelación completa de su morfología y se recubren con una capa vegetal que acaba camuflando la pátina del tiempo que dejan las cortas de extracción. Lo mismo ocurre con las instalaciones y la maquinaria; aunque son elementos patrimoniales y símbolos de la evolución técnica minera, la restauración obliga a su desmantelamiento. Un caso de este tipo es la restauración del centro minero de As Pontes en Coruña, también realizado por ENDESA, que explota el yacimiento hasta el 2007. Tras sesenta años de actividad ininterrumpida, la producción de lignito deja afectada una enorme superficie de $24 \mathrm{~km}^{2}$, compuesta por el enorme hueco minero y la escombrera, que dejan el paisaje totalmente alterado y contaminado (Hermosillo et al., 2017). A partir de 1985 arranca un gran esfuerzo de restauración de la escombrera que discurre en paralelo a la explotación. A pesar de que la normativa en ese momento es aún poco exigente, la empresa pone en marcha un proyecto ambicioso y poco habitual que, además del acondicionamiento del suelo y de las aguas contaminadas por la pirita, procede a la revegetación de su superficie. Posteriormente (2008-2012), como parte del Plan de Cierre, el hueco minero se convierte en un lago artificial de aguas limpias, mientras que la escombrera ya está revegetada y dignamente integrada en el paisaje. Hoy en día, lo que antes fue la mayor explotación a cielo abierto de España, da lugar a una zona de alta calidad paisajística, incluso mayor que la situación previa y un rico ecosistema con posibilidades de aprovechamiento. No obstante, estas intervenciones no evitan que las gigantescas máquinas de extracción se destruyan, borrando con ello los testimonios de los avances técnicos en el centro minero de As Pontes y por tanto la fisionomía y la memoria del lugar.
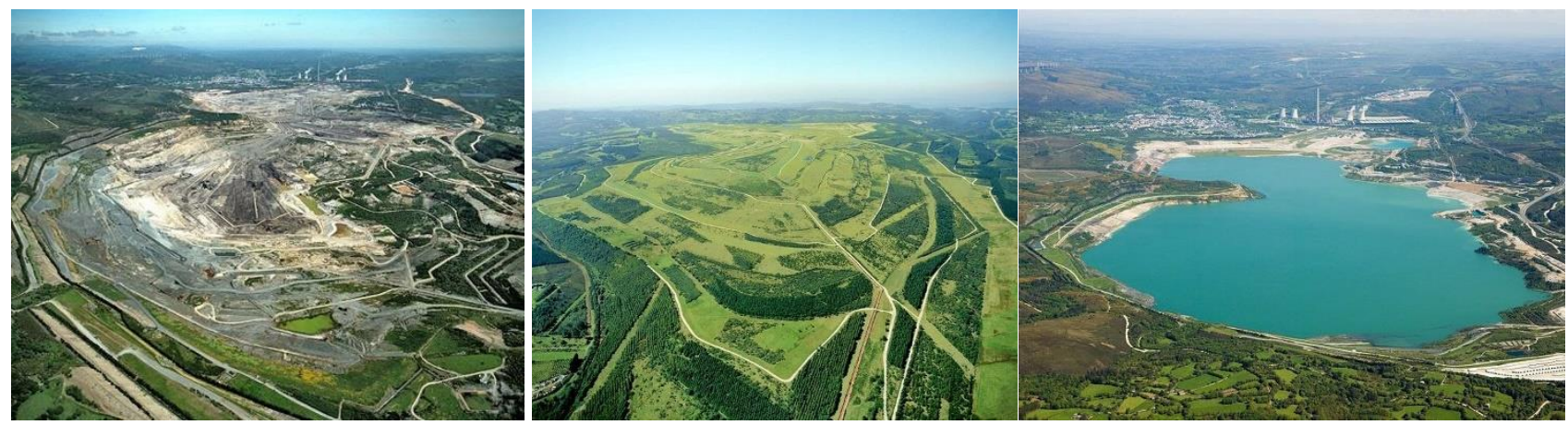

Fig. 07, 08, 09 Restauración de la mina de As Pontes, en Coruña: antes y después. Fuente: (Hermosillo et al., 2017) 


\section{Cuando los escombros generan patrimonio: la recuperación de las Minas de Ríotinto}

La identificación de valores en los conjuntos y la consciencia de las posibilidades que contemplan dan lugar a proyectos patrimoniales, que combinan la preservación de la memoria con la remediación ambiental. La recuperación de las Minas de Ríotinto en Huelva, una de las zonas mineras más antiguas del mundo, destaca como la más paradigmática y pionera en este sentido. La explotación intensiva de los yacimientos de oro, cobre y plata deja el territorio sometido a una grave contaminación, causada por los efluentes ácidos y los minerales pesados que se vierten al Río Tinto, contaminando las aguas y los suelos y provocando alteraciones irreversibles en toda la cuenca. Al mismo tiempo, con la crisis del sector y el cierre de las explotaciones en los 80 , la comarca queda expuesta a serios problemas socioeconómicos. A la vista del deterioro medioambiental, la Junta de Andalucía impulsa en los 90 un ambicioso plan de rehabilitación ${ }^{3}$ orientado principalmente a suprimir la contaminación del río y del suelo, disminuir el impacto paisajístico de la extracción, introducir en los terrenos abandonados usos forestales o sociales y evitar fenómenos erosivos. Para cumplir con los objetivos planteados, se implementan medidas correctoras y actuaciones de regeneración ambiental que acaban dando resultados alentadores. En 1988 se crea la Fundación Río Tinto y, cuatro años después, se redacta el proyecto del Parque Minero destinado a fomentar el turismo cultural como alternativa de regeneración socioeconómica. El Parque agrupa los elementos más representativos del territorio para interpretar su pasado: el antiguo hospital que se rehabilita como Museo Minero; la corta a cielo abierto de la Peña de Hierro que, tras una serie de labores de desescombro, limpieza y acondicionamiento permite apreciar las impresionantes formaciones geológicas de la Faja Pirítica; la barriada victoriana de Bella Vista y, quizás el atractivo más significativo, el recorrido en el ferrocarril minero a lo largo de unos $11 \mathrm{~km}$ de la antigua vía recuperada, acompañada por la presencia del propio Río Tinto, con sus características aguas rojizas y los márgenes amarillentos. Numerosas edificaciones, vías férreas, pequeñas estaciones, estériles y escorias se preservan y se funden con el entorno natural, ofreciendo al visitante una imagen auténtica del paisaje minero (Delgado, 2012). Siendo consciente del valor de su legado, la comunidad local participa activamente en la creación del parque y su contribución resulta catalizadora.

La recuperación de las Minas del Ríotinto resulta paradigmática, debido a que la exigencia de eliminar los efectos de la contaminación no impide la valorización del patrimonio. Los grandes contrastes cromáticos que dejan a la vista las labores extractivas, las modificaciones del relieve por las cortas y la acumulación de escombros, son alteraciones características de la Faja Pirítica, fruto de la acción antrópica desde hace más de 4.500 años, y se convierten en componentes de memoria e identidad. Las labores restauradoras se realizan en paralelo con la preservación de los vestigios, generando una convergencia entre el patrimonio natural y cultural-minero que está presente en todo el Parque. Los elementos pasivos se convierten en activos al servicio del uso turístico y cultural, y, al recibir más de 90.000 visitantes al año, el Parque Minero constituye actualmente el referente más importante del país y pionero de su tipo a nivel internacional ${ }^{4}$.

\footnotetext{
3 "Plan de mejora ambiental de las cuencas de los ríos Tinto y Odiel", Junta de Andalucia, 1996

${ }^{4}$ Más información en TSIOUTI, A y SABATÉ B., J. (2018), p. 94, 221
} 

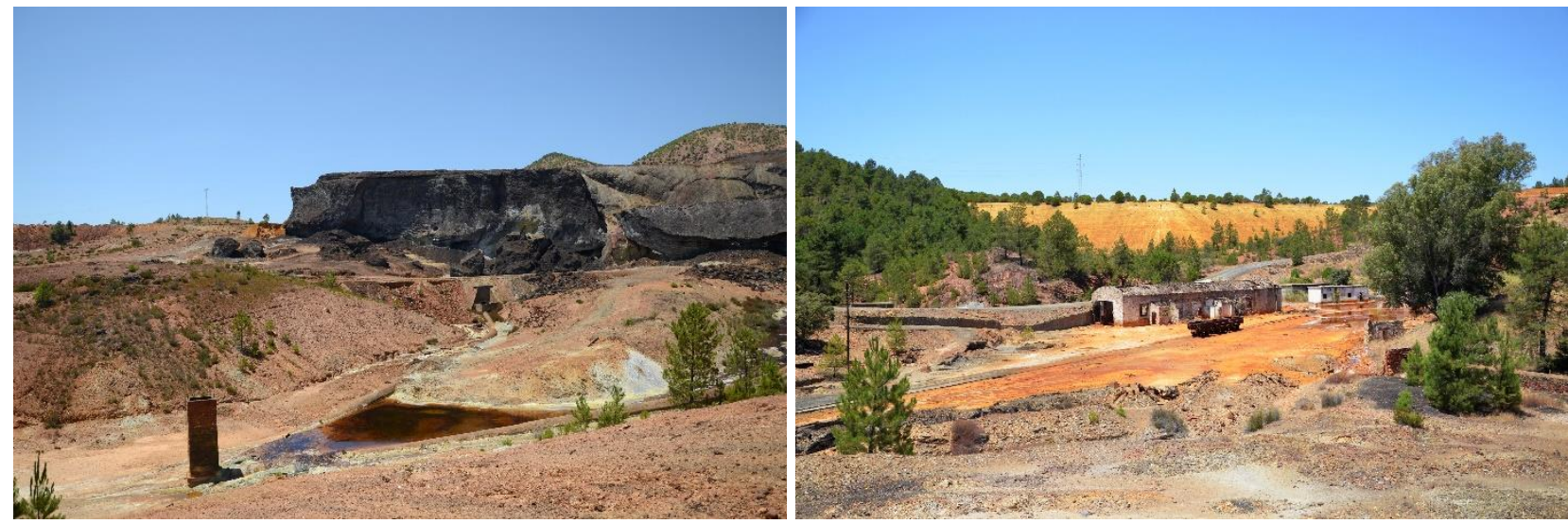

Fig. 10, 11 Parque Minero del Ríotinto: el paisaje explotado en vista. Fuente: Archivo personal de la autora.

\section{Conclusiones}

El recorrido muestra un esfuerzo por equilibrar el aprovechamiento de los recursos minerales con la paliación de la contaminación mediante disposiciones legales que cada vez se hacen más rigurosas y estrictas. Las prácticas de restauración siguen una tendencia paralela a la normativa, empezando por intervenciones sencillas de corrección de las alteraciones, como sucede en las canteras de Cuchía en Cantabria o en La Revilla, en Segovia. La exigencia de minimizar los impactos da lugar a algunos proyectos relevantes que, una vez cumplidas las obligaciones legales, dan lugar a nuevos paisajes de alta calidad ecológica, aptos para acoger nuevos usos, siendo paradigmáticas algunas experiencias restauradoras de ENDESA.

Los ejemplos muestran sensibilidad ambiental, motivada por la obligación de cumplir con las exigencias legales mínimas, por una parte, y por la necesidad de devolver los espacios mineros a la comunidad en un estado digno y renovado, por la otra, aprovechando sus posibilidades de recibir nuevas funciones. Sin embargo, la preocupación por corregir la contaminación acaba dando casi exclusividad a este aspecto, con lo que los valores patrimoniales de los sitios pasan a segundo plano. Especialmente en los lugares muy contaminados, se requieren acciones intervencionistas que en muchas ocasiones acaban eliminando tanto la maquinaria y las instalaciones, como el paisaje mismo, e incluso las técnicas innovadoras, la memoria histórica y la cultura minera. Este es el caso de las Minas de As Pontes, donde la rehabilitación de la gran escombrera y la transformación del hueco minero en un lago artificial generan un rico ecosistema, pero acaban eliminando la identidad y memoria del lugar.

Al ser agentes de contaminación, los paisajes mineros en desuso son objeto de rechazo por parte de la sociedad. Pero previamente habían sido fuentes de riqueza y generadores de empleo, y con la evolución de las técnicas y la industrialización de las labores se convierten en símbolos de progreso. Cuando se toma consciencia de estos valores, así como de su potencial para estimular un nuevo desarrollo local, se ponen en marcha iniciativas orientadas a la preservación del legado minero. Hoy en día, España cuenta con diversas actuaciones de este tipo que resultan alentadoras. La puesta en valor de las Minas de Ríotinto demuestra que, cuando se refuerza el espíritu comunitario y el orgullo de la gente por su patrimonio, y cuando se consigue confluencia y buena colaboración entre los agentes públicos y privados, la contaminación acaba dando resultados positivos. Al contrario, si la comunidad no lo reclama, el patrimonio se pierde. En As Pontes por ejemplo, que en su momento fue la mayor explotación a cielo abierto de España, nadie se interesó por las impresionantes máquinas y otros vestigios patrimoniales que existían en el lugar. No se plantea ninguna cautela para preservarlos y por tanto se acaban perdiendo para cumplir con los objetivos de la rehabilitación ambiental. Mejores resultados en este sentido ofrecen otros procesos de puesta en valor que arrancan de la comunidad local, o bien la involucran.

A pesar de las numerosas restauraciones ambientales realizadas, la normativa minera vigente todavía no llega a solucionar la problemática de la inmensa cantidad de explotaciones abandonadas y en estado de degradación. Los proyectos singulares anteriormente expuestos, representan una parte mínima de las 
explotaciones y parten de iniciativas públicas o privadas que pretenden reaprovechar los terrenos, yendo más allá de la ley. A pesar de su actualización continua con disposiciones cada vez más precisas, la normativa vigente sigue presentando indefiniciones y vacíos que las empresas aprovechan para incumplir con sus responsabilidades. En Cataluña se da un caso paradigmático, el de las minas de potasa de Súria y Sallent, donde la mala gestión de los residuos mineros por la empresa explotadora (Iberpotash) contamina gravemente la zona y genera peligros para la salud de las personas. La cuenca del río Llobregat sufre la salinización por la potasa, y el entorno circundante está expuesto a riesgos de subsidencia y otros perjuicios. El caso de la comarca del Bages genera, entre otros, conflictos y reacciones por parte de la sociedad, con lo que se puede argumentar que, a pesar de su renovación sucesiva desde los 80 , la legislación minera no resulta suficiente para controlar los impactos ambientales y sociales de la minería en su integridad. La valorización del legado minero se condiciona, pues, por factores que van más allá de la normativa; la implicación de la comunidad local en los procesos, la voluntad de las empresas explotadoras, el potencial existente de las zonas, son algunos de los que más destacan.

\section{BIBLIOGRAFÍA}

\section{Obra completa}

DELGADO, A. D. (coord.) (2012). Catálogo del Museo Minero de Ríotinto. Fundación Río Tinto. Grupo de investigación HUM 838 de la universidad de Huelva.

ESCRIBANO B., M. M. (2015). Los espacios mineros abandonados. El caso de la comunidad de Madrid. Tesis doctoral. Universidad Politécnica de Madrid. Director: Escribano, B. R.

HERMOSILLO, M. A. et al. (2017). Cuatro acciones en centros mineros de ENDESA. Madrid: ENDESA

LUENGO, A. y MARÍN, C. (1999). El jardín de la sal. Santa Cruz de Tenerife: Ecotopía, D.L.

TANDY, C. et al. (1979). Industria y paisaje. Madrid: Instituto de Estudios de Administración Local.

TSIOUTI, A. y SABATÉ B., J. (2018). Lo tangible y lo intangible: interpretando memorias en el paisaje minero: de los casos españoles a la mina de Amiantos en Chipre. Trabajo Final de máster. ETSAB, UPC.

\section{Revistas}

SAIZ DE OMEÑACA, J. (1996). La "reconversión ambiental" de la minería a cielo abierto en España. Revista Informes de la Construcción. Vol. 47. Consejo Superior de Investigaciones Científicas.

SABATÉ BEL, J. (2005). De la preservación del patrimonio a la ordenación del paisaje. Revista Identidades. Territorio, Cultura, Patrimonio., vol. 1, pp. 15-33.

\section{Ordenanzas o Decretos}

Junta de Andalucía (1996). Medio Ambiente en Andalucía. Informe 1996. Consejería del medio ambiente y ordenación del territorio. Plan de mejora ambiental de las cuencas de los ríos Tinto y Odiel. Sevilla: Novograf, S.A.

Ministerio de Industria y Energía (2009). Real Decreto 975/2009, de 12 de junio, sobre gestión de los residuos de las industrias extractivas y de protección y rehabilitación del espacio afectado por actividades mineras. 
Ministerio de Industria y Energía (1984). Orden de 20 de noviembre de 1984 por la que se desarrolla el Real Decreto 2994/1982, de 15 de octubre, sobre restauración del espacio natural afectado por actividades mineras. «BOE» núm. 285, de 28 de noviembre de 1984, páginas 34301 a 34302

Ministerio de Industria y Energía (1984). Real Decreto 1116/1984, de 9 de mayo, sobre restauración del espacio natural afectado por las explotaciones de carbón a cielo abierto y el aprovechamiento racional de estos recursos energéticos.

Ministerio de Industria y Energía (1982). Real Decreto 2994/1982, de 15 de octubre, sobre restauración de espacio natural afectado por actividades mineras. «BOE» núm. 274, de 15 de noviembre de 1982, páginas 31246 a 31247

\section{Fuentes electrónicas}

http://www.landformining.igeo.ucm-csic.es/sites/default/files/files/La\%20Revilla_RG_19_ENE.pdf

(Consulta: 02/03/2019)

https://www.solvay.es/es/solvay-in/locations/restauracion_de_la_cantera_de_cuchia.html

(Consulta: 27/02/2019) 